\title{
Dynamic compressive behavior of foamed polyethylene film
}

\author{
Kohei Tateyama ${ }^{1}$, Hiroyuki Yamada $^{2, \text { a }}$, Nagahisa Ogasawara ${ }^{2}$, Ryo Okui $^{3}$, and Kinya Ogawa ${ }^{4}$ \\ ${ }^{1}$ Graduate Student, School of Systems Engineering, National Defense Academy, Kanagawa 239-8686, Japan \\ ${ }^{2}$ School of Systems Engineering, National Defense Academy, Kanagawa 239-8686, Japan \\ ${ }^{3}$ Foam Development Center, Sekisui Chemical Co., LTD., Saitama 616-8255, Japan \\ ${ }^{4}$ Institute of Space Dynamics, Kyoto 616-8255, Japan
}

\begin{abstract}
The foamed film as the shock absorption material has attracted much attention because it is thin $(100 \mu \mathrm{m} \sim 400 \mu \mathrm{m})$ and has a closed cell structure. However, the dynamic mechanical properties have not been reported in the foamed film. The purpose of this study is to elucidate the compressive behavior of the foamed polyethylene film at the wide strain rate range. First, the new compressive test apparatus for the dynamic strain rate, the drop-weight testing machine with opposed load cell, was developed, which can be also evaluated the dynamic stress equilibrium of the specimen. It is confirmed that the compressive flow stress increased with increasing the strain rate, regardless of the film thickness. The foamed polyethylene film has the high strain rate sensitivity in the quasi-static deformation. On the other hand, there is almost no change of the strain rate sensitivity in the dynamic and the impact deformation. In order to investigate the mechanism of strain rate dependence, the foamed polyethylene film was observed by X-ray computed tomography scanner before and after compressive test. The fracture of the closed cell only occurred in the quasi-static deformation. It was clarified that the strain rate sensitivity of the foamed film depends strongly on that of the construction material, polyethylene.
\end{abstract}

\section{Introduction}

Smartphones and tablet computers have become more popular than cell phones and laptop computers in recent years. Most of these devices have a thin and large display, which show weakness in the impact such as falling or collision. The shock absorption ability is required in order to protect the display and substrate. Recently, a foamed polyethylene film as the shock absorption materials have attracted much attention, because it is thin $(100 \mu \mathrm{m} \sim$ $400 \mu \mathrm{m})$ and has a closed cell structure.

Mechanical properties of the general foamed material, such as polymeric and metal foams, have been intensively studied. It has been clarified that these materials have strain rate sensitivity of the stress-strain relationship [1-5]. In addition, the polymeric foams show remarkable strain rate sensitivity: an increased elastic modulus, an increased plateau stress and a decreased densification strain in comparison with metal materials, since the base material have viscoelastic properties [2-4]. However, the mechanical properties and measurement methods have not been reported in the foamed film, since this material is newly developed in recent years. Therefore, it is necessary to clarify the strain rate dependence of compressive deformation of the foamed film as the shock absorption materials.

The authors have reported the impact compressive properties of foamed polyethylene film using a split Hopkinson pressure bar (SHPB) method with the circular tube having a flange [5]. However, the SHPB method is a generally accepted test method for strain rates in the

\footnotetext{
${ }^{a}$ Corresponding author: ymda@nda.ac.jp
}

range $10^{2}-10^{5} \mathrm{~s}^{-1}$, which does not include the dynamic strain rate of $10^{0}-10^{1} \mathrm{~s}^{-1}$. The mechanical properties of the dynamic strain rate were required for the shock absorption materials.

In the present study, the effect of strain rate on the compressive behavior of the foamed polyethylene film was investigated. We attempt to use the dropweight testing machine with opposed load cell for the dynamic compressive properties. Furthermore, the foamed polyethylene film of before and after compressive test was observed by X-ray computed tomography scanner to clarify the mechanism of strain rate dependence.

\section{Experimental procedures}

\subsection{Material}

A commercial closed cell foamed polyethylene film (hereinafter referred to as foamed PE film) with a density of $330 \mathrm{~kg} / \mathrm{m}^{3}$ was used (XLIM-WF01, Sekisui Chemical Co., Ltd.). The specimen with thickness of approximately 300 and $400 \mu \mathrm{m}$ were prepared. The foamed PE film has features such as water resistance, chemical resistance and abrasion resistance. Figure 1 shows the surface and crosssectional images of foamed PE film, which are observed using the digital microscope and the scanning electron microscope (SEM). It can be confirmed that the cell surfaces have no holes, and all cell is closed. In addition, the flattened cell was observed in the thickness direction, since the foamed PE film was produced by extrusion foaming. Compressive testing specimens with thickness of approximately $300 \mu \mathrm{m}$ and $400 \mu \mathrm{m}$ and diameter of $30 \mathrm{~mm}$ were prepared by using a hollow punch with circular razor.

This is an Open Access article distributed under the terms of the Creative Commons Attribution License 4.0, which permits unrestricted use, distribution, and reproduction in any medium, provided the original work is properly cited. 

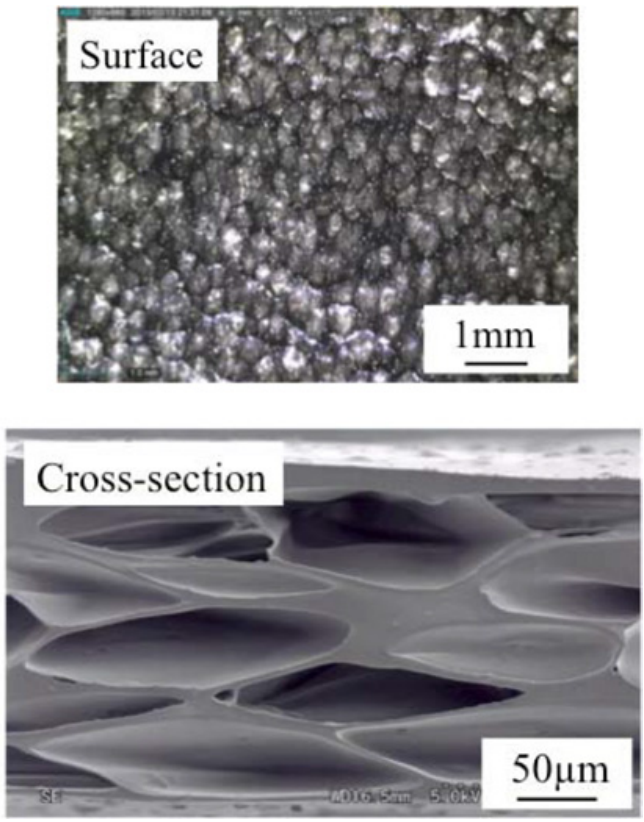

Figure 1. Surface and cross-section of Foamed film.

\subsection{Quasi-static test}

The quasi-static compression test was conducted using the universal testing machine.

The quasi-static compression test was carried out at the initial strain rates of approximately $1.7 \times 10^{-3}, 1.7 \times$ $10^{-2}$ and $1.7 \times 10^{-1} \mathrm{~s}^{-1}$. The test was conducted three times for each strain rate.

\subsection{Dynamic test}

The dynamic compression test was performed using the drop-weight testing machine with opposed load cell (hereinafter referred to as drop-weight testing machine). This testing machine was consisted of a drop-weight, guide rail and a load cell. A recording system is comprised of a Wheatstone bridge box, a differential amplifier (5305, NF Corporation), and a digital oscilloscope (DL750, Yokogawa Meters \& Instruments Co.). Figure 2 shows the schematic view of a drop-weight testing machine and stress wave propagation in this testing machine. The load cell of drop-weight testing machine is composed of a stress detection part and a stress transmission part that was made of the T6-tempered 2024 aluminum alloy.

When the compressive stress wave reaches the interface between the detection part and the stresstransmitted bar, part of the stress wave reflects back into the detection part, while the remaining part of the wave propagates through the stress-transmitted bar. By considering the load equilibrium and the continuity of particle velocity at the interface, the following equations are obtained [6]:

$$
\begin{aligned}
A_{1}\left(\sigma_{11}+\sigma_{12}\right) & =A_{2} \sigma_{21} \\
\frac{1}{\rho C}\left(\sigma_{11}-\sigma_{12}\right) & =\frac{1}{\rho C} \sigma_{21}
\end{aligned}
$$

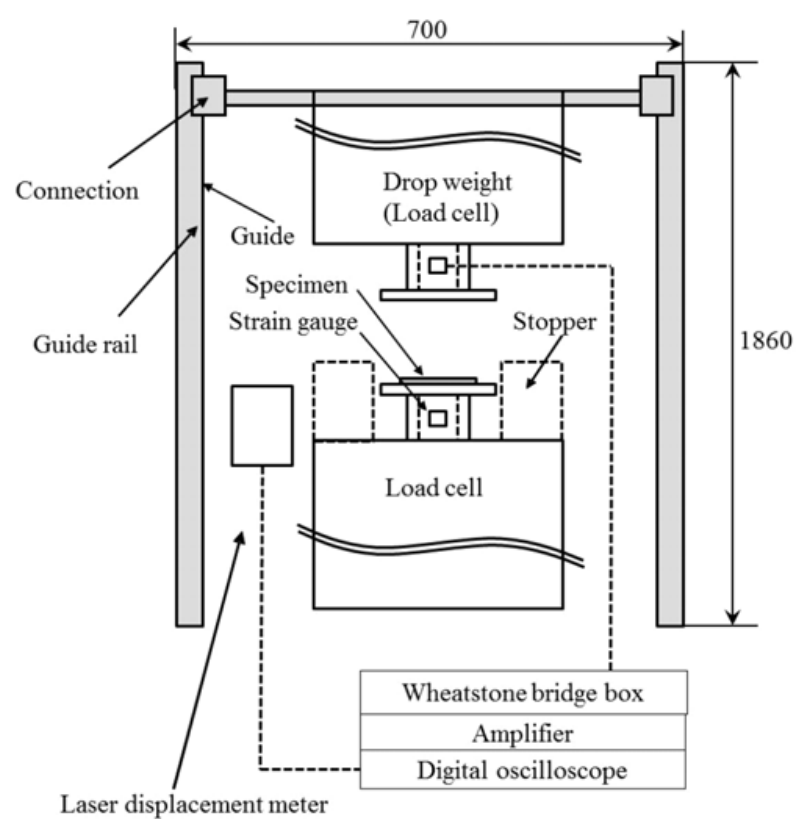

Figure 2. Setup of the drop-weight testing machine with opposed load cell for dynamic test.

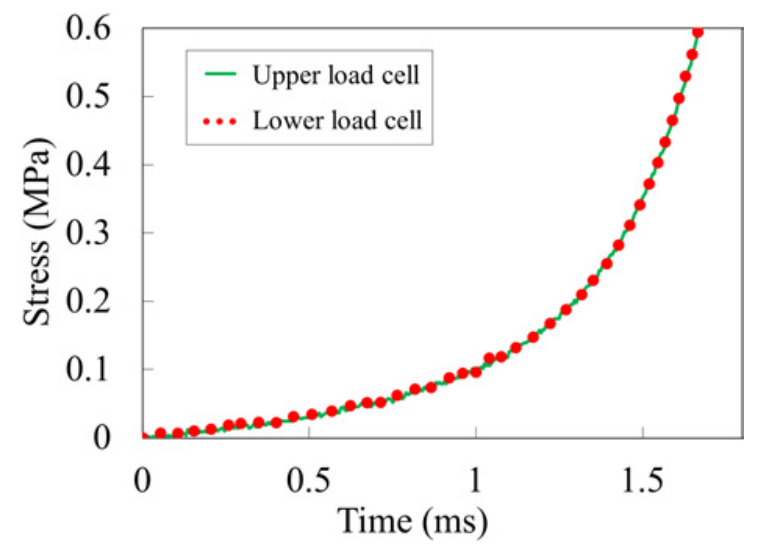

Figure 3. Time histories of applied stresses on each load cells at the dynamic test.

where $\sigma_{11}, \sigma_{12}$ and $\sigma_{21}$ are the incident, reflected and transmitted stress waves at the interface between the detection part and the stress-transmitted bar, respectively, $A_{1}$ is the cross-sectional area of the detection part, $A_{2}$ is the cross-sectional area of the stress-transmitted bar, and $C$ and $\rho$ are the velocity of the elastic wave and the density of the apparatus, respectively. From Eqs. (1) and (2), the following relationships are obtained:

$$
\sigma_{21}=\frac{2}{1+A_{2} / A_{1}} \sigma_{11}
$$

If $A_{2} \gg A_{1}$, then $\sigma_{21} \ll \sigma_{11}$. Thus, the effect of the reflected stress wave from the bottom of the transmitted bar is very small when $\sigma_{21} \ll \sigma_{11}$. This implies that the compressive stress deformation can be detected for a long time without any disturbances since this apparatus ignores the reflected stress wave. In this study, the value of $A_{1}$ was $132 \mathrm{~mm}^{2}$ and the value of $A_{2}$ was $13100 \mathrm{~mm}^{2}$.

The displacement of the drop-weight is measured by a laser displacement meter (KEYENCE: LK-G5000V). 


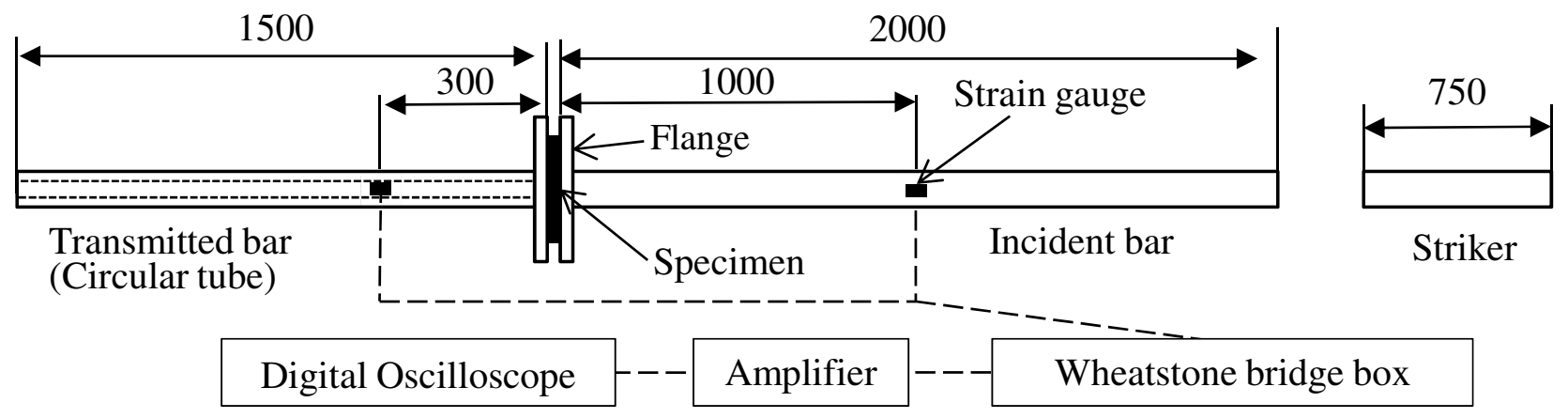

Figure 4. Setup of the SHPB apparatus for the impact compression test.

The impact compression test was carried out at approximately $5.0 \times 10^{1} \mathrm{~s}^{-1}$.

The drop-weight testing machine with opposed load cell have the two load cells at top and bottom of apparatus. The upper load cell used as drop-weight. It is possible to evaluate the dynamic stress equilibrium of the specimen by measuring the upper and lower load history in the same way as SHPB method. Figure 3 shows the stress-time relationship in dynamic test at both ends of the specimen. The compression test was carried out In the dynamic test, the dynamic stress equilibrium is achieved within the specimen, as shown in Fig. 3.

\subsection{Impact test}

The impact compression test was performed using the SHPB method established by Kolsky [7,8]. Generally, SHPB method is used solid bar adapted to the specimen diameter. If the impact test of the foamed film specimen with the diameter of $30 \mathrm{~mm}$ was performed by the solid bars, the poor measurement sensitivity was indicated because of the low strength. In the previous study [5], we proposed that the transmitted bar has a smaller crosssectional area and a lower elastic modulus indicated the high sensitivity of the load measurements of specimen. The circular tube having a flange that was made of the 2024 aluminum alloy was used as the transmitted bar. In addition, an attempt was made to be high sensitivity of measurement of the incident stress wave using the incident bar having a flange.

Figure 4 shows the setup of the SHPB apparatus for the impact compression test, which consisted of a striker, an incident bar, a transmitted bar. The incident and striker bars made of stainless steel ISO 4301-304-00-I was $16 \mathrm{~mm}$ in diameter. The transmitted bar was consisted of the circular tube, which was made of the T6- tempered 2024 aluminum alloy with the outside diameter of $16 \mathrm{~mm}$ and the inside diameter of $12 \mathrm{~mm}$. The incident bar and transmitted bar have a flange of diameter of $32 \mathrm{~mm}$.

By applying elementary one-dimensional elastic wave propagation theory [9-11], the nominal stress $(\sigma(t)$, nominal strain $(\varepsilon(t))$, and strain rate $(\dot{\varepsilon}(t)$ in the foamed PE film specimen can be determined as follows:

$$
\begin{gathered}
\sigma(t)=\frac{A_{t} E_{t} \varepsilon_{t}(t)}{A_{\mathrm{S}}} \\
\varepsilon(t)=\frac{1}{l_{\mathrm{S}}} \int_{0}^{t}\left[2 c_{i} \varepsilon_{i}(t)-\left(c_{i} \frac{A_{t} E_{t}}{A_{i} E_{i}}+c_{t}\right) \varepsilon_{t}(t)\right] d t
\end{gathered}
$$

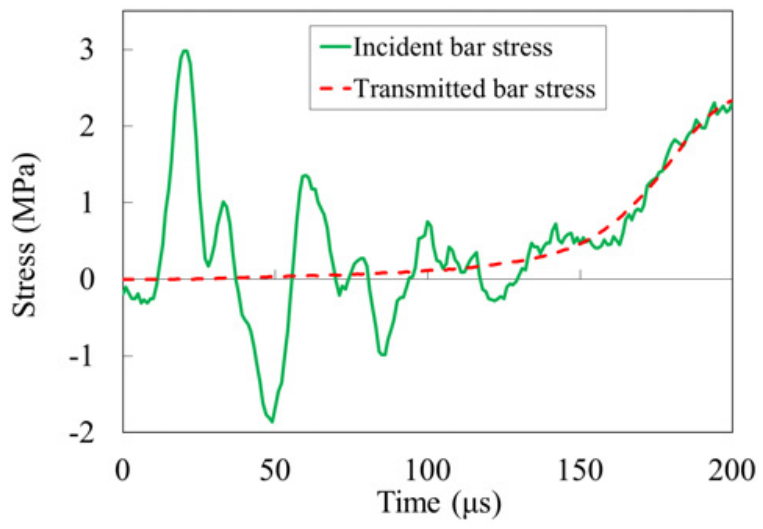

Figure 5. Time histories of applied stresses on each face of specimen at the impact test.

$$
\dot{\varepsilon}(t)=\frac{1}{l_{\mathrm{S}}}\left[2 c_{1} \varepsilon_{i}(t)-\left(c_{1} \frac{A_{2} E_{2}}{A_{1} E_{1}}+c_{2}\right) \varepsilon_{t}(t)\right]
$$

where $A_{i}$ and $A_{t}$ are the cross-sectional area of the incident and transmitted bars, $E_{i}$ and $E_{t}$ are the Young's modulus of the incident and transmitted bars, respectively. $\varepsilon_{i}(t), \varepsilon_{r}(t)$ and $\varepsilon_{t}(t)$ are the incident, reflected and transmitted waves, respectively. $C_{i}(=5300 \mathrm{~m} / \mathrm{s})$ and $C_{t}(=5100 \mathrm{~m} / \mathrm{s})$ are the velocity of the elastic wave in the incident and transmitted bars, respectively. In the present study, the nominal stress, nominal strain, and strain rate in the foamed PE film specimen were evaluated using Eqs. (4) to (6). The impact compression test was carried out at the typical initial strain rate of approximately $5.0 \times 10^{3} \mathrm{~s}^{-1}$.

Figure 5 shows the axial stress histories at both ends of the specimen in the impact test. The stress fluctuation was observed immediately after the loading, which is assumed due to the vibration of flange. In the SHPB method using the circular tube with flange, both ends of the specimen are achieved the stress equilibrium, which show the high sensitivity for measurement of the impact load.

\section{Results and discussion}

\subsection{Stress-strain relationship}

Figure 6 shows the typical stress-strain relationship for the foamed PE film with a thickness of $300 \mu \mathrm{m}$ and $400 \mu \mathrm{m}$. The flow stress increased with the increase in strain rate and the plateau deformation was observed immediately after the compressive testing started in the foamed PE 


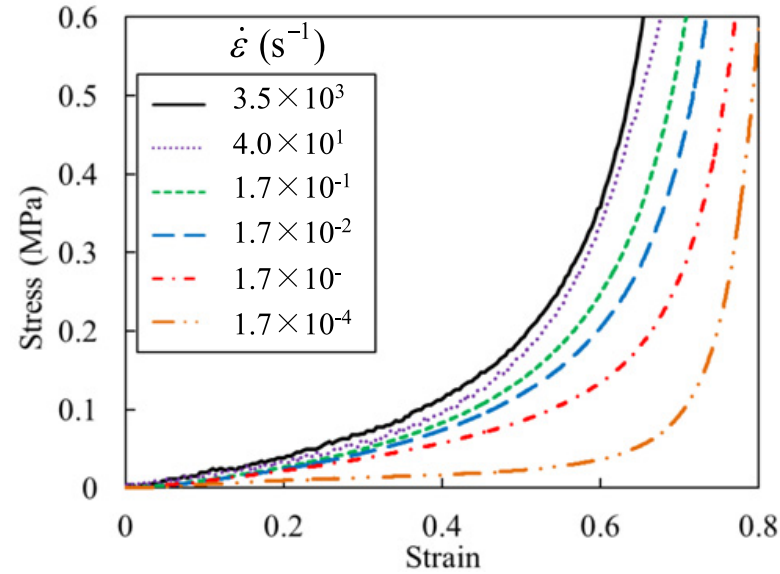

(a) $300 \mu \mathrm{m}$

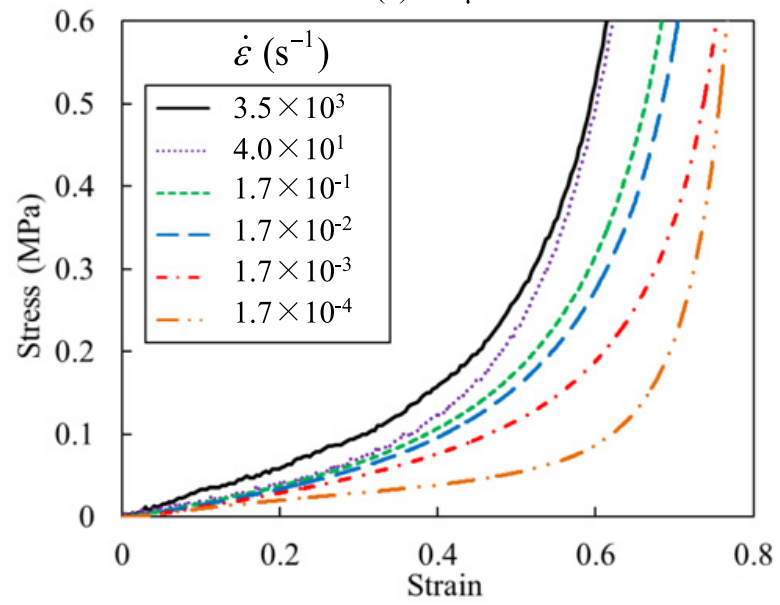

(b) $400 \mu \mathrm{m}$

Figure 6. Typical stress-strain relationship of the PE film specimen with thickness of $300 \mu \mathrm{m}$ (a) and $400 \mu \mathrm{m}$ (b).

film with a thickness of $300 \mu \mathrm{m}$ and $400 \mu \mathrm{m}$. This trend of deformation process was the same as the thickness of $100 \mu \mathrm{m}$ specimen [5]. Thus, it was revealed that the deformation mechanism of the foamed PE film was not affected by the thickness of specimen.

\subsection{Effect of strain rate}

In order to investigate the effect of the strain rate on the compressive stress of the foamed PE film in detail, the variation in compressive stress was plotted as a function of strain rate using a double logarithm at each strain $(\varepsilon=$ $0.2-0.5$ ), as shown in Fig. 8. Each plot is the average of 3-4 data. The rate of increase in the stress at each strain, which was caused by the increasing strain rate, was calculated as follows:

$$
\sigma=C \dot{\varepsilon}^{\alpha}
$$

where $C$ is the constant value, which was unrelated to the strain rate. $\alpha$ is the increase rate in stress with increasing strain rate. In the present study, value of $\alpha$ was defined as the strain rate sensitivity at each strain. Table 1 shows the strain rate sensitivity at each strain obtained from the stress-strain relationship for the foamed PE film.

Both in the thickness of $300 \mu \mathrm{m}$ and $400 \mu \mathrm{m}$ specimens, the strain rate sensitivity at $\dot{\varepsilon} \leq 1.7 \times 10^{-2} \mathrm{~s}^{-1}$

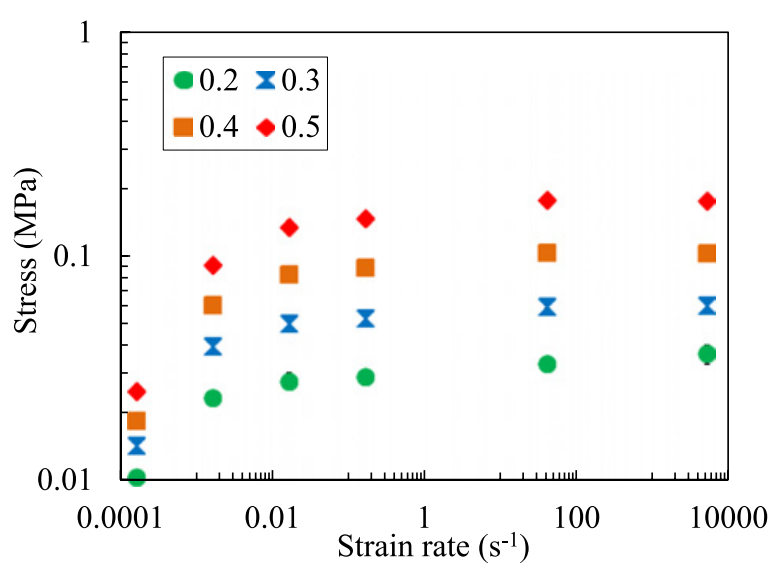

(a) $300 \mu \mathrm{m}$

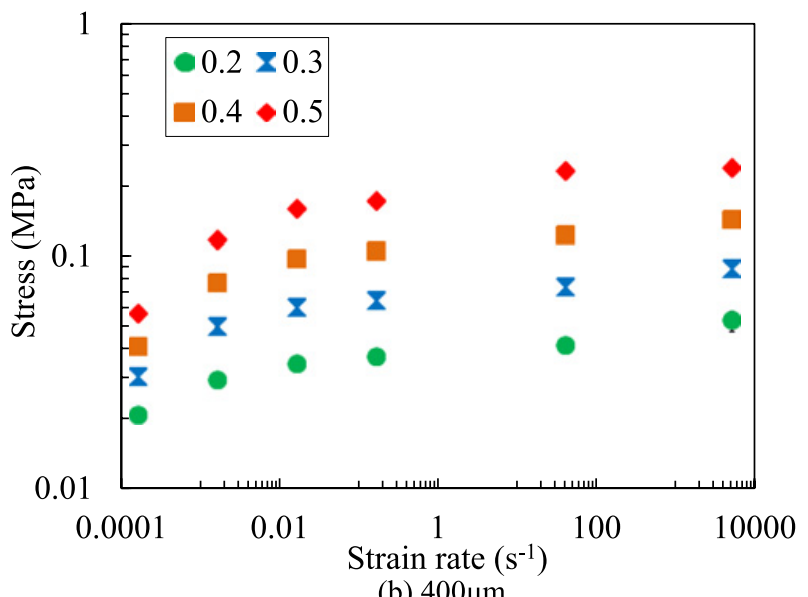

Figure 7. The variation in compressive stress plotted as a function of strain rate using a double logarithm at each strain with thickness of $300 \mu \mathrm{m}$ (a) and $400 \mu \mathrm{m}$ (b).
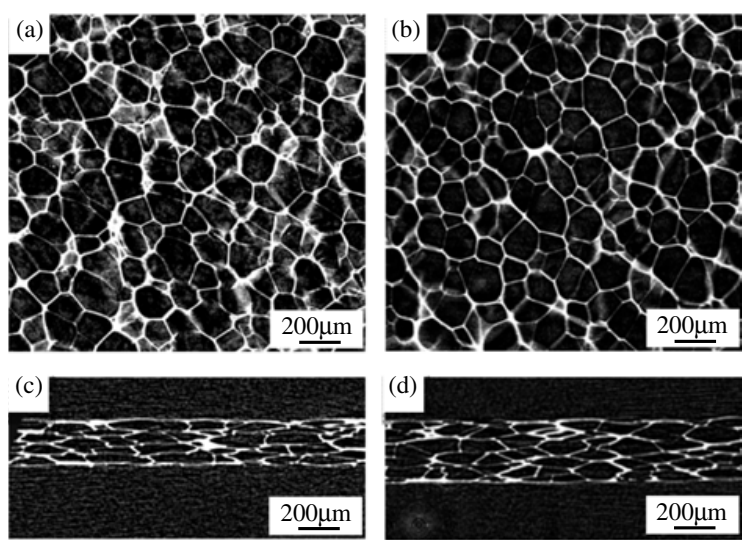

Figure 8. The cross-sectional CT images of the radial direction (a: $300 \mu \mathrm{m}, \mathrm{b}: 400 \mu \mathrm{m}$ ) and the thickness direction (c: $300 \mu \mathrm{m}, \mathrm{d}$ : $400 \mu \mathrm{m})$ in the foamed PE film.

was increased with increasing the strain. On the other hand, the strain rate sensitivity at $\dot{\varepsilon} \geq 1.7 \times 10^{-2} \mathrm{~s}^{-1}$, which indicates that the strain rate dependence of strength between the quasi-static and impact deformation, show the low value and done not change with increasing the strain. It has been reported $[1,3]$ that the foamed polymer material such as the polystyrene foam had the high strain rate sensitivity above the dynamic strain rate when compared 
Table 1. The strain rate sensitivity at each strain obtained from the stress-strain relationship for the foamed PE film.

\begin{tabular}{|c|c|c|c|}
\hline Thickness $(\mu \mathrm{m})$ & \multirow{2}{*}{$\varepsilon$} & \multicolumn{2}{|c|}{$\alpha$} \\
\cline { 3 - 4 } & & $\begin{array}{c}\leq 1.7 \times 10^{-2} \\
\text { (Quasi-static) }\end{array}$ & $\begin{array}{l}\geqq 1.7 \times 10^{-2} \\
\begin{array}{c}\text { (Quasi-static } \\
\rightarrow \text { Impact) }\end{array}\end{array}$ \\
\hline \multirow{4}{*}{300} & 0.2 & 0.080 & 0.020 \\
\cline { 2 - 4 } & 0.3 & 00.11 & 0.021 \\
\cline { 2 - 4 } & 0.4 & 00.14 & 0.023 \\
\cline { 2 - 4 } & 0.5 & 00.18 & 0.026 \\
\hline \multirow{3}{*}{400} & 0.2 & 00.069 & 0.038 \\
\cline { 2 - 4 } & 0.3 & 00.079 & 0.030 \\
\cline { 2 - 4 } & 0.4 & 00.10 & 0.030 \\
\cline { 2 - 4 } & 0.5 & 00.13 & 0.032 \\
\hline
\end{tabular}

Table 2. The detailed cell shape measured from the threedimensional images in the foamed PE film.

\begin{tabular}{|c|c|c|c|c|}
\hline $\begin{array}{c}\text { Thickness } \\
(\mu \mathrm{m})\end{array}$ & $\begin{array}{c}\text { Max. length, } \\
L_{\max }(\mu \mathrm{m})\end{array}$ & $\begin{array}{c}\text { Min. length, } \\
L_{\min }(\mu \mathrm{m})\end{array}$ & $\begin{array}{c}\text { Aspect } \\
\text { ratio }\end{array}$ & $\begin{array}{c}\text { Cell size } \\
(\mu \mathrm{m})\end{array}$ \\
\hline 300 & 368 & 60 & 6.1 & 234 \\
\hline 400 & 398 & 70 & 5.6 & 214 \\
\hline
\end{tabular}

to quasi-static strain rate. It was cleared that foamed PE film has the different strain rate sensitivity in comparison with general polymeric foam material.

The flow stress at the specimen with the thickness of $400 \mu \mathrm{m}$ is higher than that of $300 \mu \mathrm{m}$, regardless of strain rate. Theoretically, the thickness of $300 \mu \mathrm{m}$ and $400 \mu \mathrm{m}$ specimens made by same material and the same density does not show the difference in flow stress. This difference was assumed to be due to the cell shape.

\subsection{Effect of cell shape}

In order to investigate the effects of cell shape on the strength, a three-dimensional measurement was performed using X-ray CT apparatus (Yamato Scientific Co., TDM1000H-II). The maximum image resolution of the $\mathrm{X}$-ray CT is $2.4 \mu \mathrm{m}$. Figure 8 shows the cross-sectional CT images of the radial direction and the thickness direction in the thickness of $400 \mu \mathrm{m}$ specimen. It can be confirmed that all cells are closed. Additionally, it is clarified that there is little anisotropy of the cell shape in the thickness direction.

Table 2 shows the detailed cell shape measured by the CT images in the thickness of $300 \mu \mathrm{m}$ and $400 \mu \mathrm{m}$ specimens. The aspect ratio was calculated as $L_{\max } / L_{\min }$, and the cell size was calculated as $\left(L_{\max }+\right.$ $\left.L_{\min }\right) / 2$. Each parameter was an average of approximately 100 measurements. The cell size and aspect ratio at the thickness of $400 \mu \mathrm{m}$ specimen is higher than that of $300 \mu \mathrm{m}$ specimen. It is clear that thickness of $300 \mu \mathrm{m}$ specimen is more flattened in the radial direction compared to that of $400 \mu \mathrm{m}$, which leads to the resistance due to the bending deformation of the cell wall.
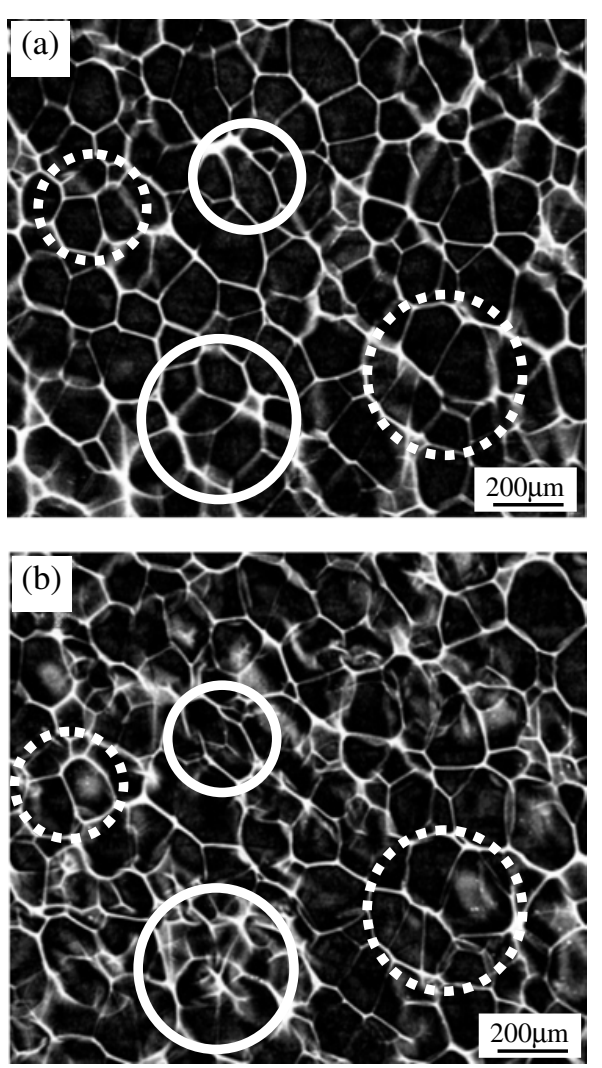

Figure 9. CT images at the radial direction of before or after quasi-static test at the foamed PE film with thickness of $400 \mu \mathrm{m}$ (a) before, b) after).

\subsection{Effect of the trapped gas in closed cell}

It has been reported by Bouix et al. [2] that the trapped gas does not have enough time to escape from the foam until the cell is totally collapsed during the impact deformation using a fluid chamber, which is responsible for the strain rate dependence of strength in the polypropylene foam materials. However, it is necessary to confirm whether the inside air of cells flowed out due to the fracture of the closed cell, because the foamed PE film have very high ductility for the tensile deformation. We have to investigate the behavior of inside air of PE foamed film before and after the quasi-static compression test and the impact compression test, respectively. However, it is difficult to perform the direct observation of the outflow of air. Thus, the CT image was used to observe the deformation of the cell structure before and after compression test.

Figure 9 shows the CT images at the radial direction of before and after the quasi-static test in the thickness of $400 \mu \mathrm{m}$ specimens. The test condition is the strain rate of $1.7 \times 10^{-3} \mathrm{~s}^{-1}$ and the strain of 0.8 . As shown in the white dotted circle, the cell structure keeps its shape before and after the quasi-static test. On the other hand, the cell wall was fractured by the compressive deformation in the area enclosed by the white solid line, which would lead to the outflow of air from the cell. It was reported [12] that the outflow from the pore was caused by the deformation resistance in the micro-cell structure. In the 

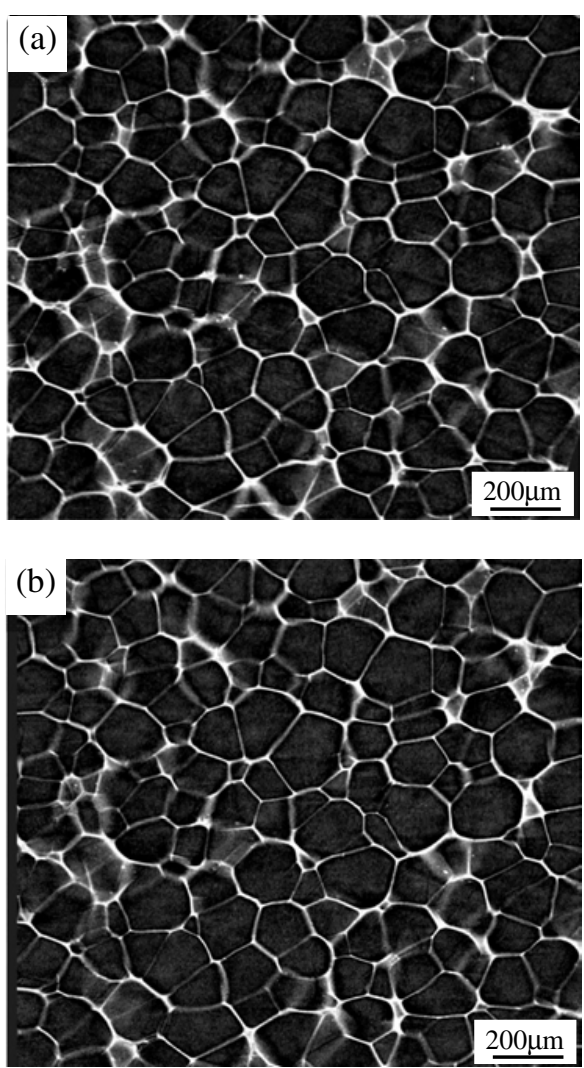

Figure 10. CT images at the radial direction of before or after impact test at the foamed PE film with thickness of $400 \mu \mathrm{m}$ (a) before, b) after).

quasi-static compressive deformation of the foamed PE film, the increase in the strain rate sensitivity was shown due to the outflow resistance along with the fracture of the cell wall.

Figure 10 shows the CT image at the radial direction of before and after the impact test in the thickness of $400 \mu \mathrm{m}$ specimens. The test condition was strain rate of $4.0 \times 10^{2} \mathrm{~s}^{-1}$ and the strain of 0.8 . It was revealed that the cell collapse did not occur in the impact deformation. This is because the strength of the cell wall made by the polyethylene was increased due to the increase in strain rate. Thus, it is inferred that the inside air does not flow out during the impact compressive deformation.

\section{Summary}

To investigate the effect of the strain rate on the compressive behavior of the foamed PE film, a wide strain rate range test were performed. The results can be summarized as follows.

(1) The new compressive test apparatus for the dynamic strain rate, the drop-weight testing machine with opposed load cell, was developed, which can be evaluated the dynamic stress equilibrium of the specimen.

(2) The compressive flow stress increased with increasing the strain rate, regardless of the thickness.

(3) The plateau deformation was observed immediately after the compressive testing started and no linearelastic response phase was observed in the foamed PE film specimen, regardless of the thickness.

(4) The foamed PE film has the high strain rate sensitivity in the quasi-static deformation, which is due to the outflow resistance along with the fracture of the cell wall.

(5) There is almost no change of the strain rate sensitivity in the dynamic and the impact deformation.

This study was supported in part by the Grant-in-Aid for Young Scientists (A) (Grant No. 25709004) from the Ministry of Education, Culture, Sports, Science and Technology, Japan. The authors are deeply grateful to Mr. Mizukami and Mr. Ishihara, undergraduate student at the National Defense Academy, for their assistance.

\section{References}

[1] J. Zhang, N. Kikuchi, V. Li, A. Yee, G. Nusholtz, Int. J. Impact Eng. 21 (1998), 369-386

[2] R. Bouix, P. Viot, J. L. Lataillade, Int. J. Impact Eng. 36 (2009), 329-342

[3] O. Ouelleta, D. Croninb and M. Worswick, Polymer Testing 25 (2006), 731-743

[4] P. Viot, Int. J. Imp. Eng. 36 (2009), 975-989

[5] H. Yamada, K. Tateyama, R. Okui, N. Ogasawara, K. Ogawa, J. Jpn. Soc. Exp. Mech. 14 (2014), 153-157

[6] K. Ogawa, J. Soc. Mat. Sci. Japan 54 (2005)

[7] H. Kobayashi, K. Horikawa, K. Ogawa, M. Hori, J. Sol. Mech. Mat. Eng. 3 (2009), 64-71

[8] B. Hopkinson, Phil. Trans. Roy. Soc., A 213 (1914), 437-452

[9] H. Kolsky, Proc. Phys. Soc. B 62 (1949), 676-700

[10] K. Ogawa, J. Jpn. Inst. Light Met. 52 (2001), 131-135

[11] K. Ogawa, H. Kobayashi, F. Sugiyama and K. Horikawa, JSME International Journal, A 48 (2005), 228-233

[12] L.J. Gibson, M.F. Ashby, (M. Otsuka translated), Cellular Solids (Uchida Roukakuho, 1993) 